\title{
Two new nematode species (Plectida: Leptolaimidae,Rhadinematidae) from Chatham Rise, New Zealand
}

\author{
Daniel Leduc ${ }^{\text {Corresp. } 1}$ \\ ${ }^{1}$ National Institute of Water and Atmospheric Research (NIWA), Wellington, New Zealand \\ Corresponding Author: Daniel Leduc \\ Email address: Daniel.Leduc@niwa.co.nz
}

Two new species of the order Plectida are described from Chatham Rise, New Zealand. Leptolaimus dififtinus sp. nov. is characterised by the short body 319-420 microns long, truncate labial region slightly offset from body contour and bearing conspicuous outer labial papillae, cephalic setae 1.3-1.4 microns long, amphid located 4-9 microns from anterior end, lateral alae originating from middle of buccal cavity length, female without supplements, male with precloacal and postcloacal pairs of subventral setae, nine tubular supplements (alveolar supplements absent), tubular supplements weakly S-shaped with pointed tip, spicules arcuate 24 microns or 1.4 cloacal body diameters long and dorsal gubernacular apophyses. Lavareda iramscotti sp. nov. is characterised by adult body length 3023-3121 microns long, eight longitudinal rows of body pores each with short papilla, cephalic setae 4-5 microns long, tail 146-165 microns long, male with spicules 54 microns long, gubernaculum with triangular apophyses, 20 precloacal supplements with bifid distal tips arranged in $9+1+10$ pattern, female with vulva at $55 \%$ of body length from anterior and cuticularisation perpendicular to vagina at level of vulva. The present study provides the first record of a Leptolaimus species from the New Zealand region and the first description of a female specimen of the genus Lavareda. 
1

2 Two new nematode species (Plectida: Leptolaimidae, 3 Rhadinematidae) from Chatham Rise, New Zealand 4 5

6 7

8 9

10

11

12

13

Daniel Leduc

National Institute of Water and Atmospheric Research (NIWA), Wellington, New Zealand

Corresponding Author:

Daniel Leduc

301 Evans Bay Parade, Wellington, 6021, New Zealand

Email address: Daniel.Leduc@niwa.co.nz 


\section{Abstract}

Two new species of the order Plectida are described from Chatham Rise, New Zealand. Leptolaimus dififtinus sp. nov. is characterised by the short body $319-420 \mu \mathrm{m}$ long, truncate labial region slightly offset from body contour and bearing conspicuous outer labial papillae, cephalic setae 1.3-1.4 $\mu \mathrm{m}$ long, amphid located 4-9 $\mu \mathrm{m}$ from anterior end, lateral alae originating from middle of buccal cavity length, female without supplements, male with precloacal and postcloacal pairs of subventral setae, nine tubular supplements (alveolar supplements absent), tubular supplements weakly S-shaped with pointed tip, spicules arcuate $24 \mu \mathrm{m}$ or 1.4 cloacal body diameters long and dorsal gubernacular apophyses. Lavareda iramscotti sp. nov. is characterised by adult body length 3023-3121 $\mu \mathrm{m}$, eight longitudinal rows of body pores each with short papilla, cephalic setae 4-5 $\mu \mathrm{m}$ long, tail 146-165 $\mu \mathrm{m}$ long, male with spicules $54 \mu \mathrm{m}$ long, gubernaculum with triangular apophyses, 20 precloacal supplements with bifid distal tips arranged in $9+1+10$ pattern, female with vulva at 55\% of body length from anterior and cuticularisation perpendicular to vagina at level of vulva. The present study provides the first record of a Leptolaimus species from the New Zealand region and the first description of a female specimen of the genus Lavareda.

\section{Introduction}

The order Plectida Gadea, 1973 comprises nematode taxa inhabiting marine, brackish, freshwater and soil habitats, as well as a few commensal and potentially parasitic taxa (Holovachov 2014).

To date, only six marine plectid species have been recorded from New Zealand waters by Allgén (1927, 1932), Ditlevsen (1930) and Leduc \& Wilson (2016). The family Leptolaimidae Örley, 1880 is a globally distributed, largely marine and brackish family with Leptolaimus de Man, 1876 one of most common and diverse plectid genus. Sixty valid Leptolaimus species are currently known (Holovachov \& Boström 2013, Tchesunov 2015, Qiao et al. 2020), but no Leptolaimus species have yet been recorded from the New Zealand region.

The Rhadinematidae Lorenzen, 1981, is a small, rare group of marine plectids comprising three genera and five valid species (Holovachov 2014, Holovachov \& Boström 2014). Two genera, viz., Cricolaimus Southern, 1914 and Lavareda da Fonsêca-Genevois, Smol \& Bezerra, 
432011 are so far known only from males. One species, Lavareda coronatus (Ditlevsen, 1930) da

44 Fonsêca-Genevois, Smol \& Bezerra, 2011 has been recorded from the New Zealand region. This species originally belonged to the genus Cricolaimus but was transferred to Lavareda based on the structure of the cheilostom (da Fonsêca-Genevois et al.2011). Here, two new species of the order Plectida are described from Chatham Rise, New Zealand: Leptolaimus dififtinus sp. nov. and Lavareda iramscotti sp. nov.

\section{Materials \& Methods}

Samples were obtained from Chatham Rise, a submarine ridge that extends eastwards from the South Island of New Zealand, over water depths ranging from ca. 250 to $3000 \mathrm{~m}$. Samples were collected from Chatham Rise during NIWA cruise TAN0705 (March-April 2007) and TAN1103 (February 2011) under Special Permit 666 granted to NIWA by the Ministry for Primary Industries. Sediment samples were collected and processed as described in Leduc (2012), using an Ocean Instruments MC-800A multicorer (core internal diameter $=9.5 \mathrm{~cm}$ ). Each sample consisted of one subcore of internal diameter $26 \mathrm{~mm}$ taken to a depth of $5 \mathrm{~cm}$. Samples were fixed in 10\% formalin and stained with Rose Bengal. Samples were subsequently rinsed on a 45 $\mu \mathrm{m}$ sieve to retain nematodes. Nematodes were extracted from the remaining sediments by Ludox flotation and transferred to pure glycerol (Somerfield \& Warwick, 1996).

Species descriptions were made as described in Leduc (2020), based on glycerol mounts using differential interference contrast microscopy and drawings were made with the aid of a camera lucida. Measurements were obtained using an Olympus BX53 compound microscope with cellSens Standard software. All measurements are in $\mu \mathrm{m}$, and all curved structures are measured along the arc. The terminology used for describing the arrangement of morphological features such as setae follows Coomans (1979). Type specimens are held in the NIWA Invertebrate Collection (Wellington).

Abbreviations:

a: body length/maximum body diameter

b: body length/pharynx length

c: body length/tail length 
72

73

74

75

76

77

78

79

80

8

82

83

84

85

86

87

88

89

90

91 Genus Leptolaimus de Man, 1876

92 = Halaphanolaimus Southern, 1914

$93=$ Aplectus Cobb, 1914

94 = Dermatolaimus Steiner, 1916

95 = Polyaimium Cobb, 1920

cbd: corresponding body diameter

$\% \mathrm{~V}: \mathrm{V} /$ total body length $\times 100$

\section{Results}

Order Plectida Gadea, 1973

Family Leptolaimidae Örley, 1880

c': tail length/anal or cloacal body diameter

L: total body length; $n$, number of specimens

$\mathrm{V}$ : vulva distance from anterior end of body

The electronic version of this article in Portable Document Format (PDF) will represent a published work according to the International Commission on Zoological Nomenclature (ICZN), and hence the new names contained in the electronic version are effectively published under that Code from the electronic edition alone. This published work and the nomenclatural acts it contains have been registered in ZooBank, the online registration system for the ICZN. The ZooBank LSIDs (Life Science Identifiers) can be resolved and the associated information viewed through any standard web browser by appending the LSID to the prefix http://zoobank.org/. The LSID for this publication is: urn:lsid:zoobank.org:pub:4689626F-D42C-464A-BB0B55D593DD3E71. The online version of this work is archived and available from the following digital repositories: PeerJ, PubMed Central and CLOCKSS. 
96 = Alveolaimus Alekseev \& Rassadnikova, 1977

97 = Boveelaimus Alekseev, 1979

98 = Tubulaimus Alekseev \& Rassadnikova, 1977

99

100

101

102

103

104

105

106

107

108

109

110

111

112

113

114

115

116

117

118

119

120

Generic diagnosis: (from Holovachov (2014)) Lateral alae present. First annule anterior to cephalic setae bases and amphids, cephalic capsule absent. Cephalic sensilla papilliform or setiform. Amphideal aperture ventrally unispiral, without central elevation. Secretory-excretory system present; excretory canal short, excretory ampulla present. Ovary branches reflexed antidromously. Alveolar or tubular supplements present in females of some species, either in pharyngeal or pre-anal regions, or in both positions. Male reproductive system diorchic. Number of supplements varies from zero to 40 for alveolar and zero to 11 for tubular; males may have both types of supplements, one or no supplements at all. Caudal glands and spinneret present or absent.

\section{Type species: L. papilliger de Man, 1876}

Remarks. The genus was revised by Holovachov and Boström (2013) who provided a key to the identification of all 58 valid species based on features of both males and females. Two species were subsequently described by Tchesunov (2015) and Qiao et al. (2020).

\section{Leptolaimus dififtinus sp. nov.}

Figs. 1-4, Table 1

urn:1sid:zoobank.org:act:C4FE8E90-6481-4E1E-9780-561C4D1D8D9E

Type locality: Northern flank of Chatham Rise, $1194 \mathrm{~m}$ water depth ( $R V$ Tangaroa voyage TAN0705, station 196 , site D15; $\left.42.6147^{\circ} \mathrm{S}, 178.3338^{\circ} \mathrm{W}\right)$. Muddy sand sediments ( $68 \%$ sand, $19 \%$ silt, $13 \%$ clay), calcium carbonate content $59.9 \%$.

Type material: Holotype male (NIWA 139251), and one paratype female (NIWA 139252), collected on 19 April 2007.

Measurements: See Table 1 for detailed measurements. 
Description: Male. Body colourless except for dense brown granules in anterior portion

122 of intestine, fusiform, strongly curved ventrally (maybe as a result of formalin fixation), strongly tapering anteriorly in pharyngeal region and posteriorly on tail. Cuticle annulated, annules ca. 1.3 $\mu \mathrm{m}$ apart; lateral alae present consisting of raised, non-annulated cuticle ca. 2.5-3.0 $\mu \mathrm{m}$ wide extending from middle of buccal cavity length (close to first body pore) to almost half of tail length. Four longitudinal rows of sublateral body pores, extending from middle of buccal cavity to two thirds of tail length, pores in pharyngeal region with short papilla, pores posterior to pharynx without papillae; epidermal glands not observed. Somatic setae absent except for a pair of subventral setae, $2 \mu \mathrm{m}$ long, anterior to cloaca, and second pair of subventral setae posterior to cloaca. Labial region truncate, slightly offset from body contour, lips fused. Inner labial sensilla indistinct; outer labial sensilla conspicuous and papillose, located on the outer surface of lips. Cephalic sensilla setiform, 0.25-0.30 cbd long. Ocelli absent. Amphideal fovea round, located at level of anterior quarter of buccal cavity. Buccal cavity uniformly tubular: cheilostom and gymnostom short, undifferentiated; stegostom tubular, with uniformly thickened lumen. Pharynx muscular, cylindrical anteriorly, with distinct oval basal bulb, distinctly cuticularized lumen from posterior to buccal cavity to near posterior end of pharynx; valvular apparatus absent. Pharyngeal glands and their orifices indistinct. Nerve ring surrounding pharynx near middle of pharynx length. Secretory-excretory system not observed. Cardia cylindrical, with posterior part embedded in intestine

Reproductive system diorchic with both testes directed anteriorly; one larger outstretched testis located to the right of intestine with globular sperm ca. $2 \mu \mathrm{m}$ in diameter, one smaller outstretched (possibly reflexed) testis located ventrally with smaller globular sperm ca. $1 \mu \mathrm{m}$ in diameter. Spicules paired, symmetrical, arcuate, 1.4 cloacal body diameter long, only slightly cuticularised; capitulum rounded, shaft and blade gradually tapering distally. Gubernaculum with lightly cuticularized, bent dorsal apophysis. Ventral precloacal seta not observed. Accessory apparatus composed of nine more or less evenly spaced midventral tubular supplements (posterior supplements appear closer together due to body curvature), ca. 16-23 $\mu \mathrm{m}$ apart, extending for $8 \mu \mathrm{m}$ from cloaca towards anterior end; alveolar supplements absent. Tubular 149 supplements weakly S-shaped, with pointed tip, 11-14 $\mu \mathrm{m}$ long, each with small drop-shaped 
150 subsurface cuticularisation immediately anterior. Tail conical; three caudal glands and spinneret 151 present.

152

153

154

155

156

157

158

159

160

161

162

163

164

165

166

167

168

169

170

171

172

173

174

175

176

177

Females. Similar to males, but without any somatic setae, lower values of 'a' and shorter tail. Reproductive system with single anterior reflexed ovary located ventrally; posterior ovary likely present but obscured by large egg in uterus. Spermathecae not observed. Vulva situated slightly posterior to mid-body. Vagina slightly anteriorly directed, short, proximal portion encircled by single sphincter muscle. Vaginal glands not observed. Supplements absent.

Diagnosis: Leptolaimus dififtinus sp. nov. is characterised by short body 319-420 $\mu \mathrm{m}$ long, truncate labial region slightly offset from body contour and bearing conspicuous outer labial papillae, cephalic setae 1.3-1.4 $\mu \mathrm{m}$ long, amphid located 4-9 $\mu \mathrm{m}$ from anterior end, lateral alae originating from middle of buccal cavity length, female without supplements, male with precloacal and postcloacal pairs of subventral setae, nine tubular supplements (alveolar supplements absent), tubular supplements weakly S-shaped with pointed tip, spicules arcuate 24 $\mu \mathrm{m}$ or 1.4 cloacal body diameters long and dorsal gubernacular apophyses.

Differential diagnosis: The new species is similar to Leptolaimus alatus Vitiello, 1971, L. sextus Holovachov \& Boström, 2013 and L. septimus Holovachov \& Boström, 2013 particularly in having distinct outer labial sensilla and a labial region offset from body contour, but also in males having relatively short spicules (less than three cloacal body diameters), four or more weakly S-shaped tubular supplements without distal discs and in a continuous row, alveolar supplements absent, and females without supplements. Leptolaimus dififtinus sp. nov. is most similar to L. alatus but can be differentiated from the latter by the slightly shorter cephalic setae (1.3-1.4 $\mu \mathrm{m}$ or $0.25-0.30 \mathrm{cbd}$ versus $1.5-2.0 \mu \mathrm{m}$ or $0.30-0.50 \mathrm{cbd})$, anterior body pores with short papillae (versus long setae in L. alatus), number of precloacal supplements (9 versus 6-8 supplements in L. alatus) and shape of the gubernacular apophysis (bent and dorsally-directed versus plate-like and dorsocaudally-directed in L. alatus). In the original description of L. alatus by Vitiello (1971) based on specimens from the Mediterranean, the supplements have pointed tips (as in L. dififtinus sp. nov.), however Holovachov \& Boström (2013) describe the tips as blunt in their L. alatus specimens from Skagerrak and Swedish fjords. 

length (319-420 versus 626-728 $\mu \mathrm{m}$ in L. sextus), anterior body pores with short papillae (versus

180 long setae in L. sextus), shorter spicules (24 versus 39-46 $\mu \mathrm{m}$ in L. sextus), and number and shape of precloacal supplements ( 9 supplements with pointed tips versus 5-6 supplements with bifid tips in L. sextus). Leptolaimus dififtinus sp. nov. can be differentiated from L. septimus by the shorter body length (319-420 versus $679-821 \mu \mathrm{m}$ in L. septimus), anterior body pores with short papillae (versus long setae in L. septimus), lower 'a' ratio (12-20 versus 24-37 in $L$. septimus), shorter cephalic setae (1.3-1.4 $\mu \mathrm{m}$ versus 2.5-3.5 $\mu \mathrm{m}$ in L. septimus), smaller amphid (4 versus 5-6 $\mu \mathrm{m}$ wide in L. septimus), shorter tail (2.9-3.4 versus 4.7-7.1 cloacal/anal body diameters long in L. septimus), shorter spicules (24 versus 31-34 $\mu \mathrm{m}$ in L. septimus) and number and shape of precloacal supplements (9 supplements with pointed tips versus 4-5 supplements with bifid tips in L. septimus).

Etymology: The species name is an arbitrary combination of letters (ICNZ Article 11.3) and also refers to the sampling site (D15) where the type specimens were collected.

Family Rhadinematidae Lorenzen, 1981

Genus Lavareda da Fonsêca-Genevois, Smol \& Bezerra, 2011

\section{Generic diagnosis: (modified from da Fonsêca-Genevois et al. (2011) and} Holovachov (2014)) Body long, cylindrical, slender. Cuticle annulated, lateral alae absent. Epidermal glands and body pores present or absent. Lips low, inner and outer labial papilla indistinct. Cheilostom consists of a cuticularised ring with six anteriorly directed projections (one dorsal, one ventral, and four sublateral in position). Amphideal aperture loop-shaped, ventrally unispiral. Buccal cavity funnel-shaped to tubiform. Pharynx cylindrical with posterior oval bulb, muscular. Cardia embedded in intestine. Male reproductive system diorchic or monorchic, testes directed anteriorly. Spicules relatively short, strongly curved, manubrium enlarged, gubernaculum with apophysis. Nineteen or twenty midventral precloacal tubular supplements, precloacal seta present or absent. Female without supplements.

Type species: L. decraemerae da Fonsêca-Genevois, Smol \& Bezerra, 2011 


\section{Lavareda iramscotti sp. nov.}

207

208

209

210

211

212

213

214

215

216

217

218

219

220

221

222

223

224

225

226

227

228

229

230

231

232

233

Figs. 5-7, Table 1

urn:1sid:zoobank.org:act:79592D96-3AAE-4B67-9D23-14A158799216

Type locality: Chatham Rise crest, $347 \mathrm{~m}$ water depth (RV Tangaroa voyage TAN1103, station $\left.69,41.3352^{\circ} \mathrm{S}, 178.2962^{\circ} \mathrm{E}\right)$. Sandy mud sediments (44\% sand, 55\% silt, 1\% clay).

Type material: Holotype male (NIWA 139253), one paratype female and two paratype juveniles (NIWA 139254), collected on 2 February 2011.

Measurements: See Table 1 for detailed measurements.

Description: Male. Body colourless in glycerin preparations, long, slender, uniform in diameter throughout most of body, tapering towards both ends. Cuticle annulated from posterior to cephalic setae to spinneret, annules ca. $1.2 \mu \mathrm{m}$ apart, without ornamentation or lateral differentiation. Eight longitudinal rows of body pores (two subdorsal, two subventral and four sublateral) extending from posterior to buccal cavity to tail region; each pore with a short conical papilla and connected to small, barely visible epidermal gland. Cephalic region slightly rounded, with reduced labial region. Inner labial sensilla indistinct, outer labial sensilla papilliform, four cephalic setae 0.4-0.5 cbd long. Amphideal fovea ca. $1 \mathrm{cbd}$ from anterior extremity, ventrally unispiral; corpus gelatum not observed. Buccal cavity narrow, deep, tubular, without teeth; cheilostom distinct, resembling a crown, $5 \mu \mathrm{m}$ in diameter, consisting of a cuticularized ring with six small anteriorly-directed projections (one dorsal, one ventral and four lateral in position). Pharynx muscular, gradually widening posteriorly from posterior to buccal cavity and ending in an oval posterior bulb; pharyngeal lumen cuticularized from posterior to buccal cavity and most thickly cuticularized within posterior pharyngeal bulb. Nerve ring located slightly posterior to middle of pharynx length. Cardia small, $8 \mu \mathrm{m}$ long, embedded within intestine. Secretoryexcretory system with slightly cuticularized pore located posterior to nerve ring and small ampulla; four pairs of medium to large glands with clear cytoplasm located on each side of intestine, up to $33 \times 16 \mu \mathrm{m}$, starting from ca. 1-2 cbd posterior to pharynx, followed by two pairs of glands with more opaque cytoplasm immediately posteriorly, each gland with duct extending anteriorly. 

$\mu \mathrm{m}$ long, located to the right of intestine, posterior testis reflexed, $180 \mu \mathrm{m}$ long, located ventrally relative to intestine. Mature sperm cells globular, dimorphic; 14-20 $\times 11-15 \mu \mathrm{m}$ in anterior testis, 6-7 $\times 4-5 \mu \mathrm{m}$ in posterior testis. Spicules paired, equal, 1.7 cloacal body diameters long, strongly ventrally curved and narrowing distally, with well-developed capitulum; gubernaculum strongly cuticularized with triangular, dorsocaudally directed apophyses. Twenty tubular precloacal supplements, ca. $22 \mu \mathrm{m}$ long, swollen proximally and with bifid tip, each connected to a gland near proximal end and extending anteriorly; posterior group of nine supplements situated gradually further apart anteriorly (19-52 $\mu \mathrm{m}$ distance), posterior group of ten supplements more or less equidistant from each other (39-53 $\mu \mathrm{m}$ distance), and single supplement located between the posterior and anterior groups of supplements. Precloacal seta present. Tail conical, curved ventrally, with three caudal glands and well-developed spinneret.

Female. Similar to male, but with lower 'a' ratio and smaller amphid. Reproductive system with two opposed, reflexed ovaries; anterior ovary situated to the right of intestine and posterior ovary situated to the left of intestine. Spermathecae not observed. Vulva situated slightly posterior to mid-body. Vagina straight, with thick cuticle, two vaginal glands present. Thin cuticularisation centred at level of vulva and perpendicular to vagina, ca. 1 vulval body diameter long. Sphincter muscle not observed. Supplements absent. primordium present.

Diagnosis: Lavareda iramscotti sp. nov. is characterised by adult body length 3023-3121 $\mu \mathrm{m}$, eight longitudinal rows of body pores each with a short papilla, cephalic setae 4-5 $\mu \mathrm{m}$ or 0.4-0.5 cbd long, tail 146-165 $\mu \mathrm{m}$ or 5.2-5.3 cloacal/anal body diameters long, male with spicules $54 \mu \mathrm{m}$ or $1.7 \mathrm{cbd}$ long, gubernaculum with triangular apophyses, 20 precloacal supplements with bifid distal tips arranged in $9+1+10$ pattern, female with vulva at $55 \%$ of body length from anterior and cuticularisation perpendicular to vagina at level of vulva.

Differential diagnosis: The new species differs from the two other Lavareda species, $L$. coronatus (Ditlevsen, 1930) da Fonsêca-Genevois, Smol \& Bezerra, 2011 and L. decraemerae, by the presence of longitudinal rows of body pores (versus pores absent in L. coronatus and $L$. 
263 decreamerae). Additional differences between the male of L. iramscotti sp. nov. and $L$.

264 decraemerae are: greater body length (3.0 versus $2.5 \mathrm{~mm}$ in L. decraemerae), shorter cephalic

265 setae (4-5 versus $9 \mu \mathrm{m}$ in L. decraemerae), absence of cervical setae (versus eight cervical setae

266 in L. decraemerae), longer spicules (54 versus $30 \mu \mathrm{m}$ in L. decraemerae), and number and

267 arrangement of precloacal supplements (20 supplements in 9+1+10 arrangement versus 19

268 supplements in continuous row in L. decraemerae). Furthermore, the secretory-excretory system

269 in L. decraemerae comprises five glands, two of which are located on the right of the intestine

270 and three on the left side of the intestine; Lavareda iramscotti sp. nov. is characterised by an

271 secretory-excretory system with ten glands, five located on either side of the intestine. Lavareda

272 iramscotti sp. nov. can be differentiated from L. coronatus by the higher 'a' ratio (104 versus 63

273 in L. coronatus), higher 'b' ratio (17 versus 14 in L. coronatus), lower 'c' ratio (18 versus 24 in

274 L. coronatus), presence of cephalic setae (versus absent in L. coronatus), longer tail (165 versus

$275114 \mu \mathrm{m}$ in L. coronatus), male reproductive system with two testes (versus one testis in $L$.

276 coronatus), presence of precloacal seta (versus absent in L. coronatus), and arrangement of

277 precloacal supplements $(9+1+10$ versus $9+11$ arrangement in L. coronatus).

Etymology: The species name is an arbitrary combination of letters (ICNZ Article 11.3)

which also acknowledges my colleague Scott Nodder, who owing to his persistence and bloodymindedness (the latin ira translates to wrath, anger, fury), managed to obtain the large number of sediment cores required for my postdoctoral research.

282

\section{Discussion}

284

The present study provides the first record and description of a Lavareda female. Lavareda iramscotti $\mathrm{sp}$. nov. females are characterized by two reflexed genital branches, as in the closelyrelated genus Rhadinema Cobb, 1920 and like the majority of other plectid taxa. The new species does not exhibit pronounced sexual dimorphism in features such as the buccal cavity, amphids, or tail. The diagnosis of the genus was modified to take into account the presence of body pores and epidermal glands in both sexes of the new species.

Lavareda coronatus was described from ca. $64 \mathrm{~m}$ water depth in the Colville Channel (Hauraki Gulf), North Island of New Zealand. Lavareda iramscotti sp. nov., also described from a New Zealand locality though from greater depth and further south, shows some close 
293 similarities with $L$. coronatus in the structure and size of the amphids and spicular apparatus, and 294 both species have the same number of precloacal supplements. Some of the features of $L$.

295 coronatus which differ from the new species, i.e., the apparent absence of body pores, cephalic

296 setae, and precloacal seta in L. coronatus, may conceivably be the result of poor specimen

297 condition (e.g., broken cephalic setae) or may have been missed in the original description.

298 However, given the additional differences between Ditlevsen's and my male specimens, notably 299 in the 'a', 'b', and 'c' ratios, arrangement of the precloacal supplements, and number of testes, I

300 consider it most likely that the two species are indeed different, even though they belong to a rare 301 genus and were both described from New Zealand localities.

302

303

304

305

306

307

308

309

310

311

312

313

314

315

316

317

318

319

320

321

322

323

\section{Conclusions}

The present study provides the first record of a Leptolaimus species from the New Zealand region and the first description of a female specimen of the genus Lavareda. At least a dozen additional, yet to be described Leptolaimus species inhabit continental slope environments of New Zealand (D. Leduc, unpublished data). Further research is needed to better characterise the diversity of this genus as well as that of other plectid nematodes across the region's seabed habitats.

\section{Acknowledgements}

I thank two anonymous reviewers for providing constructive criticisms on the manuscript, Scott Nodder (NIWA) for obtaining the sediment samples, as well as the participants of NIWA voyages TAN0705 and TAN1103, and the officers and crew of RV Tangaroa.

\section{References}

Alekseev VM., Rassadnikova IV. 1977. A new species and taxonomic analysis of the genus Leptolaimus (Nematoda, Araeolaimida). Zoologicheskii Zhurnal 56:1766-1774 [in Russian]

Alekseev VM. 1979. Evolution of supplementary organs in nematodes Leptolaimus and establishment of the genus Boveelaimus (Nematoda, Leptolaimidae). Zoologicheskii Zhurnal 58:1296-1301 [in Russian] 
324

325

326

327

328

329

330

331

332

333

334

335

336

337

338

339

340

341

342

343

344

345

346

347

348

349

350

351

352

353

354

355

356

357

358

359

360

361

362

363
Allgén CA. 1927. Freilebende marine Nematoden von der Küste Tasmaniens. Zoologischer Anzeiger 9:197-217

Allgén C.A. 1932. Weitere Beiträge zur Kenntnis der marinen Nematodenfauna der Campbellinsel. Nyt Magazin for Naturvidenskaberne 70:97-198

Cobb NA. 1914. The North American free-living fresh-water nematodes. Transactions of the American Microscopical Society 33:69-119

Cobb NA. 1920. One hundred new nemas (type species of 100 new genera). Contributions to a Science of Nematology 9:217-343

Coomans A. 1979. Addendum I. A proposal for a more precise terminology of the body regions in the nematode. Annales de la Societee Royale Zoologique de Belgique 108:115-117.

da Fonsêca-Genevois V, Smol N, Bezerra TN. 2011. Free-living nematodes from a colonization experiment in the upwelling area of Arraial do Cabo, Rio de Janeiro, Brazil: Lavareda decraemerae gen. n., sp. n. and emended diagnosis of Cricolaimus Southern, 1914 (Plectida: Rhadinematidae). Nematology 13:761-772

de Man JG. 1876. Onderzoekingen over vrij in de aarde levende Nematoden. Tijdschrift Nederlandsche Dierkundig Vereeiging 2:78-196

Ditlevsen H. 1930. Marine free-living Nematodes from New Zealand. (Papers from Dr. Th. Mortensen's Pacific Expedition 1914 - 16). Videnskabelige Meddelelser fra Dansk naturhistorisk Forening $i$ Kjøbenhavn 87:201-242

Gadea E. 1973. Sobre la filogenia interna de los nematodos. Publicación del Instituto de Biologiá Aplicada 54:87-92

Holovachov O., Boström S. 2013. Swedish Plectida (Nematoda). Part 4. The genus Leptolaimus de Man, 1876. Zootaxa 3739:1-99

Holovachov O. 2014. Order Plectida Gadea, 1973. Pp. 487-535 in: Schmidt-Rhaesa A. ed. Handbook of Zoology Volume 2: Nematoda. Hamburg: De Gruyter, xv + 759 pp.

Holovachov O., Boström, S. 2014. Swedish Plectida (Nematoda). Part 5. Rhadinema timmi (Vitiello, 1971) comb. n. Zootaxa 3779:477-486

Leduc D. 2012. Deep-sea nematodes (Comesomatidae) from the Southwest Pacific Ocean: five new species and three new species records. European Journal of Taxonomy 24:1-42

Peer) reviewing PDF | (2020:07:51006:1:1:NEW 16 Aug 2020) 
364

365

366

367

368

369

370

371

372

373

374

375

376

377

378

379

380

381

382

383

384

385

386

387

388

389

390
Leduc D, Wilson J. 2016. Benthimermithid nematode parasites of the amphipod Hirondellea dubia in the Kermadec Trench. Parasitology Research 115:1675-1682

Leduc D. 2020. A new nematode species, Chromadorina tangaroa sp. nov. (Chromadorida: Chromadoridae) from the hull of a research vessel, New Zealand. PeerJ 8:e9233

Örley L. 1880. Monographie der Anguilluliden. Természetrajzi Füzetek 4:1-165.

Qiao C., Jia S., Huang Y. 2020. Leptolaimus holovachovi sp. nov. (Nematoda) from Shenzhen Mangrove Nature Reserve, Shenzhen, South China. Journal of Oceanology and Limnology.

Somerfield PJ, Warwick RM. 1996. Meiofauna in Marine Pollution Monitoring Programmes: $a$ Laboratory Manual. Lowestoft: Ministry of Agriculture, Fisheries and Food.

Southern R. 1914. Nemathelmaia, Kinorhyncha, and Chaetognatha (Clare Island Survey, Part 54). Proceedings of the Royal Irish Academy 31:1-80

Steiner G. 1916. Freilebende Nematoden aus der Barentssee. Zoologische Jahrbücher 39:511664.

Tchesunov AV. 2015. Free-living nematode species (Nematoda) dwelling in hydrothermal sites of the North Mid-Atlantic Ridge. Helgoland Marine Research 69:343-384

Vitiello P. 1971. Espèces nouvelles de Leptolaimidae (Nematoda) et description du genre Leptolaimoides n. gen. Cahiers de Biologie Marine 12:419-432 
391

392

393

394

395

396

397

398

399

400

401

402

403

404

405

406

407

408

409

410

411

412

413

\section{Figure captions.}

Figure 1. Leptolaimus dififtinus sp. nov. A \& C: Anterior body region of male; B: anterior body region of female; $\mathrm{D}$ : posterior body region of female; E posterior body region of male. Scale bar: $\mathrm{A}, \mathrm{B}, \mathrm{C} \& \mathrm{D}=20 \mu \mathrm{m}, \mathrm{E}=25 \mu \mathrm{m}$.

Figure 2. Leptolaimus dififtinus sp. nov. A: Entire male; B: entire female. Scale bar: A = 25 $\mu \mathrm{m}, \mathrm{B}=20 \mu \mathrm{m}$.

Figure 3. Leptolaimus dififtinus sp. nov. light micrographs. A: Optical cross section of entire female; B: surface view of female; C: optical cross-section of entire male; D: surface view of entire male. Scale bar $=20 \mu \mathrm{m}$.

Figure 4. Leptolaimus dififtinus sp. nov. light micrographs of male. A: Optical cross-section of pharyngeal region; B: surface view of cephalic region; $\mathrm{C}$ : optical cross-section of precloacal supplements; D: tail. Scale bar: A \& B $=10 \mu \mathrm{m}, \mathrm{C} \& \mathrm{D}=11 \mu \mathrm{m}$.

Figure 5. Lavareda iramscotti sp. nov. A: Anterior body region of male; B: female cephalic region; $\mathrm{C}$ : juvenile cephalic region; $\mathrm{D}$ : male cephalic region; $\mathrm{E}$ : male posterior body region; $\mathrm{F}$ : female anterior body region; G: female posterior body region. Scale bar: $A=50 \mu \mathrm{m}, \mathrm{B}, \mathrm{C} \& \mathrm{D}=$ $20 \mu \mathrm{m}, \mathrm{E}=45 \mu \mathrm{m}, \mathrm{F}=60 \mu \mathrm{m}, \mathrm{G}=40 \mu \mathrm{m}$.

Figure 6. Lavareda iramscotti sp. nov. A: Entire male; B: female reproductive system. Scale bar: $\mathrm{A}=75 \mu \mathrm{m}, \mathrm{B}=185 \mu \mathrm{m}$.

Figure 7. Lavareda iramscotti sp. nov. light micrographs of male. A: Lateral surface view of anterior body region; B: optical cross-section of anterior body region; C: precloacal supplement; D: copulatory apparatus; E: tail tip and spinneret. Scale bar: A \& B $=10 \mu \mathrm{m}, \mathrm{C} \& \mathrm{E}=12 \mu \mathrm{m}, \mathrm{D}$ $=14 \mu \mathrm{m}$. 


\section{Table 1 (on next page)}

Morphometrics ( $\mathrm{m} \mathrm{m}$ ) of Leptolaimus dififtinus sp. nov. andLavareda iramscotti sp. nov.

Morphometrics ( $\mathrm{m} \mathrm{m}$ ) of Leptolaimus dififtinus sp. nov. and Lavareda iramscotti sp. nov. a, body length/maximum body diameter; b, body length/pharynx length; c, body length/tail length; $c^{\prime}$, tail length/anal or cloacal body diameter; cbd, corresponding body diameter; $L$, total body length; $n$, number of specimens; $\mathrm{V}$, vulva distance from anterior end of body; \%V, V/total body length $\times 100$ 
Table 1. Morphometrics ( $\mu \mathrm{m})$ of Leptolaimus dififtinus sp. nov. and Lavareda iramscotti sp. nov. a, body length/maximum body diameter; b, body length/pharynx length; c, body length/tail length; $c^{\prime}$, tail length/anal or cloacal body diameter; cbd, corresponding body diameter; L, total body length; $\mathrm{n}$, number of specimens; V, vulva distance from anterior end of body; \%V, V/total body length $\times$ 100

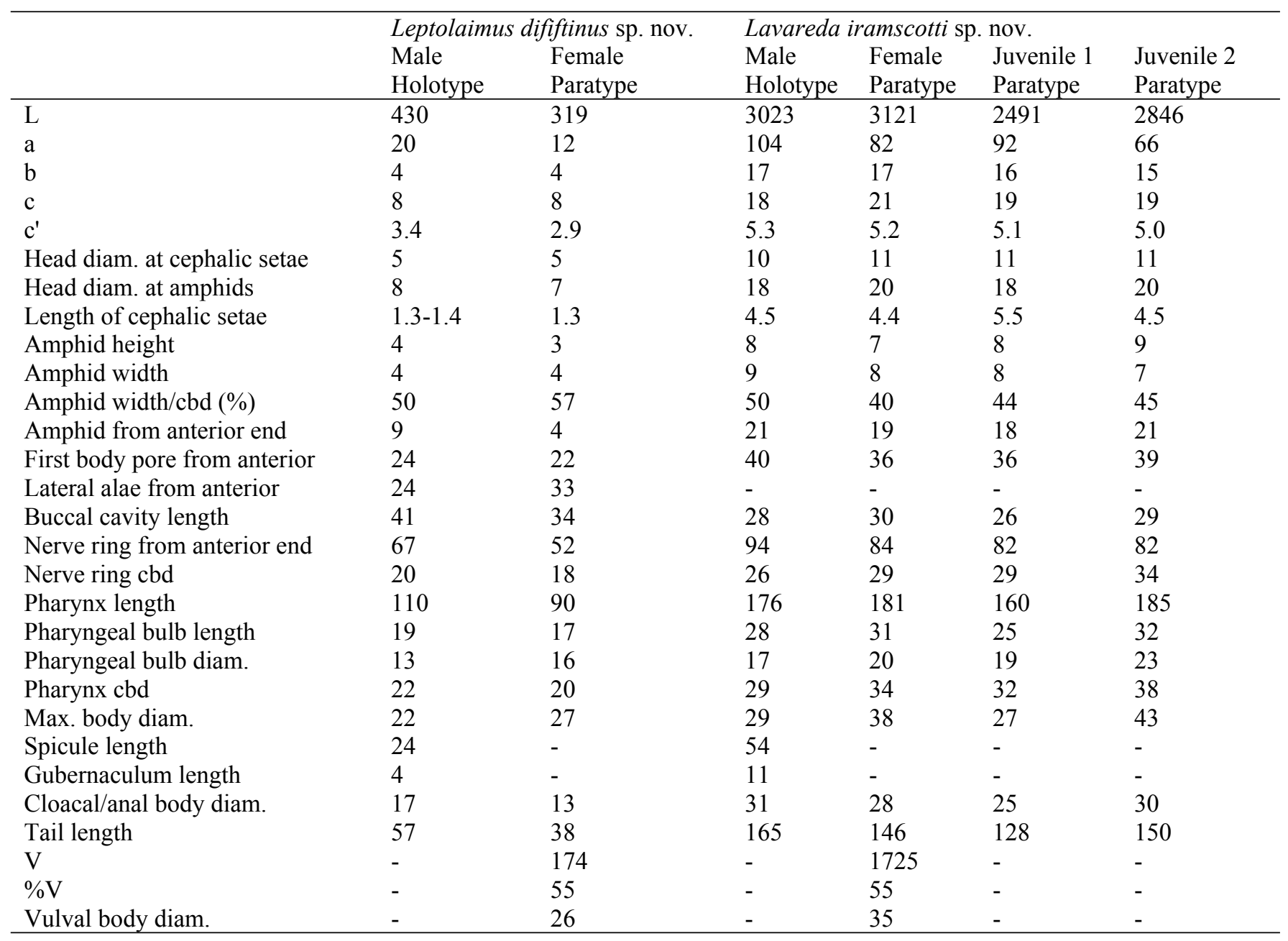


Figure 1

Leptolaimus dififtinus sp. nov. Drawings.

Leptolaimus dififtinus sp. nov. A \& C: Anterior body region of male; B: anterior body region of female; D: posterior body region of female; E posterior body region of male. Scale bar: $A, B, C \& D=20 m m, E=25 m m$. 


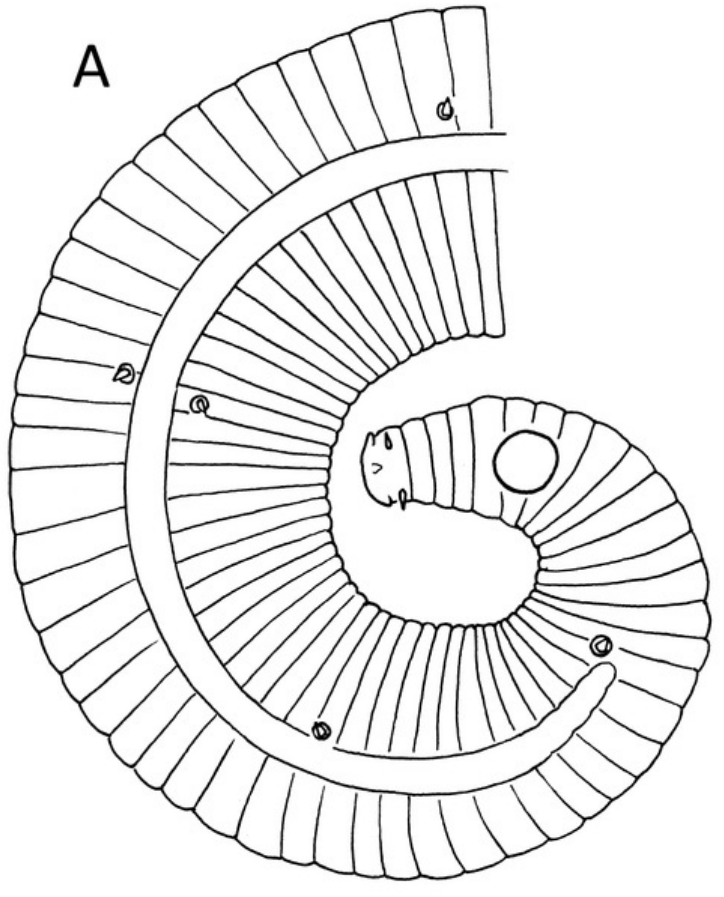

B
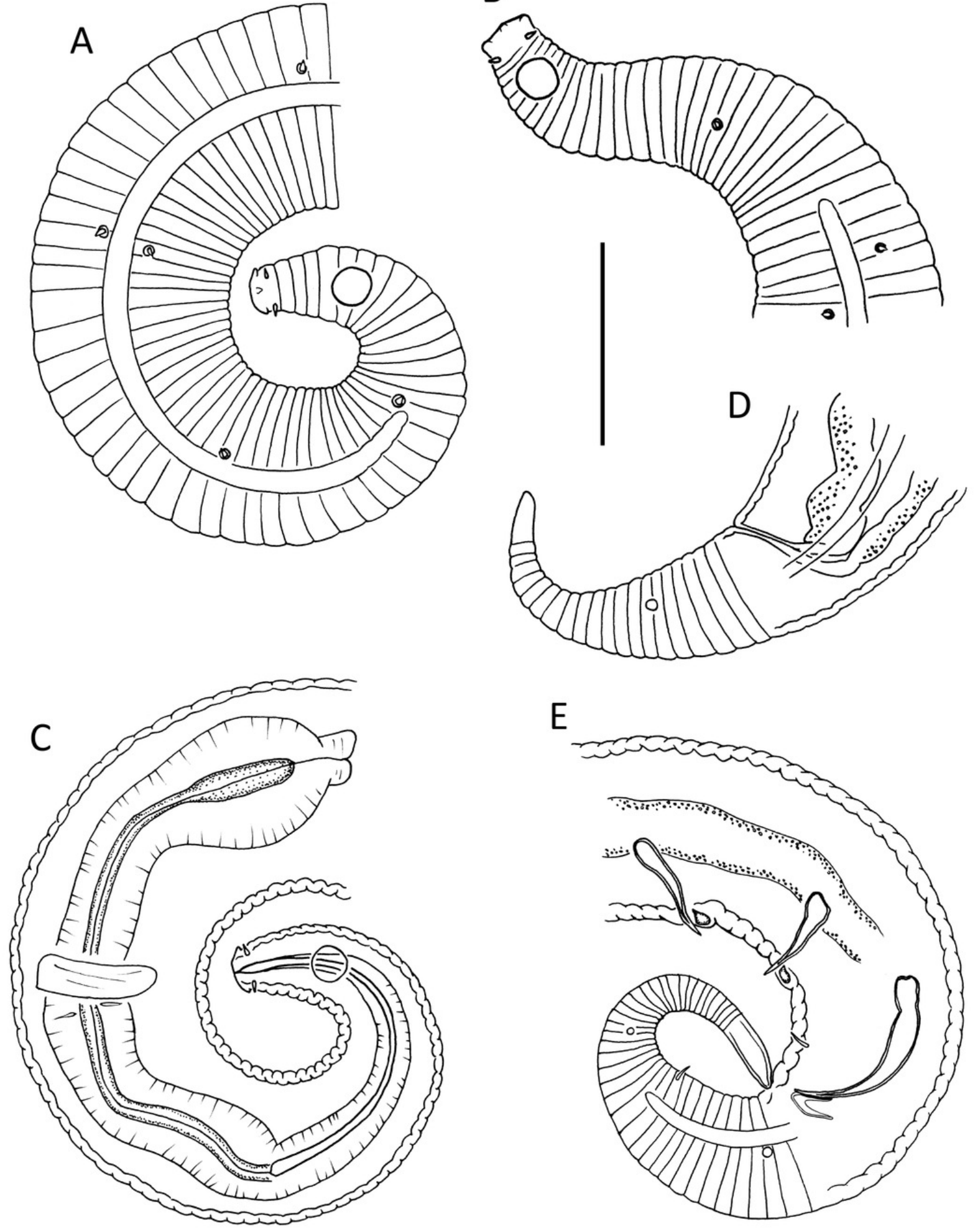
Figure 2

Figure 2. Leptolaimusdififtinus sp. nov. Drawings.

Leptolaimus dififtinus sp. nov. A: Entire male; B: entire female. Scale bar: $A=25 \mathrm{~m}$ m, B = $20 \mathrm{~m}$ m. 

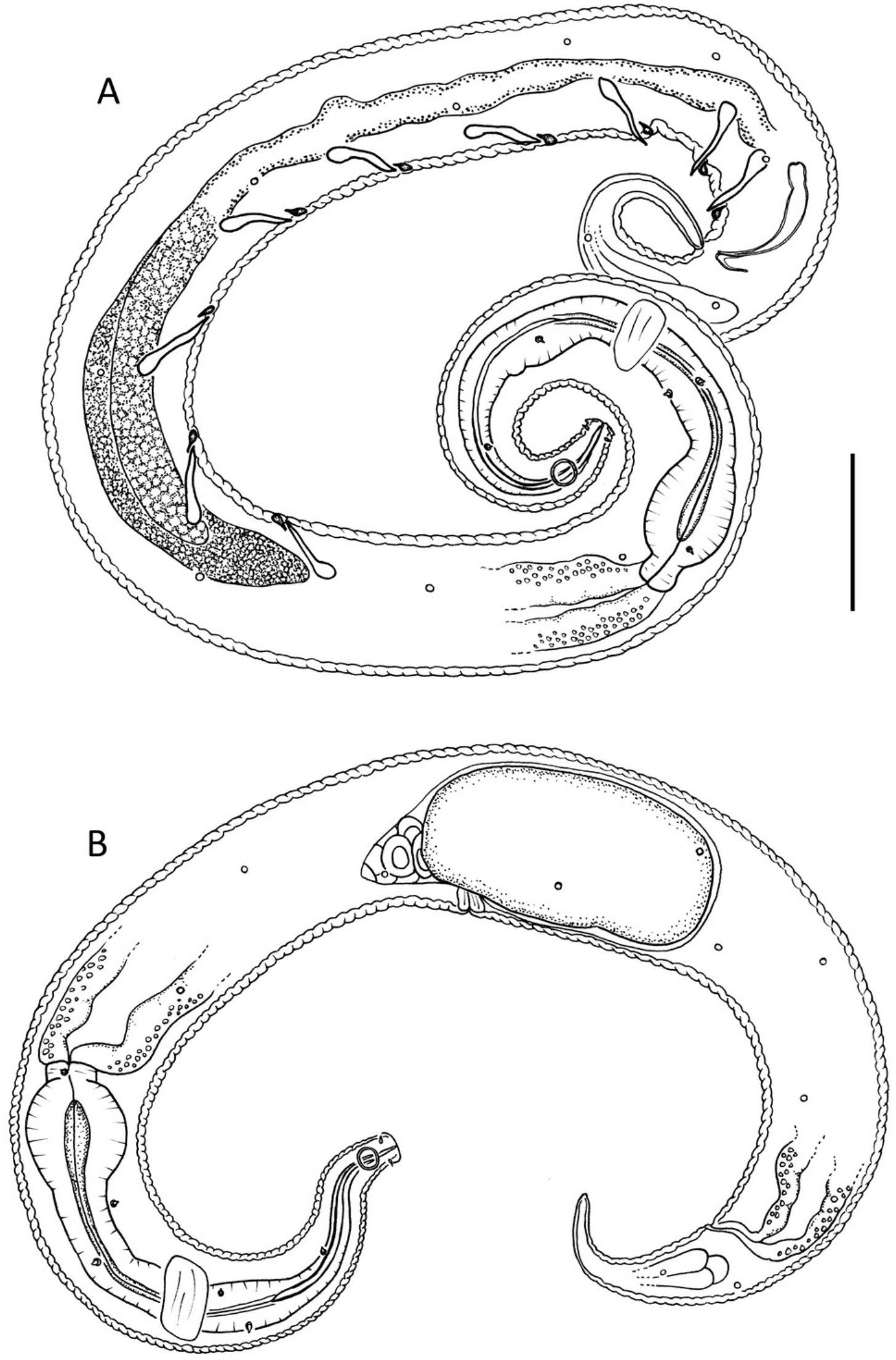
Figure 3

Leptolaimus dififtinus sp. nov. light micrographs.

Leptolaimus dififtinus sp. nov. light micrographs. A: Optical cross section of entire female; B: surface view of female; C: optical cross-section of entire male; D: surface view of entire male. Scale bar $=20$ microns. 

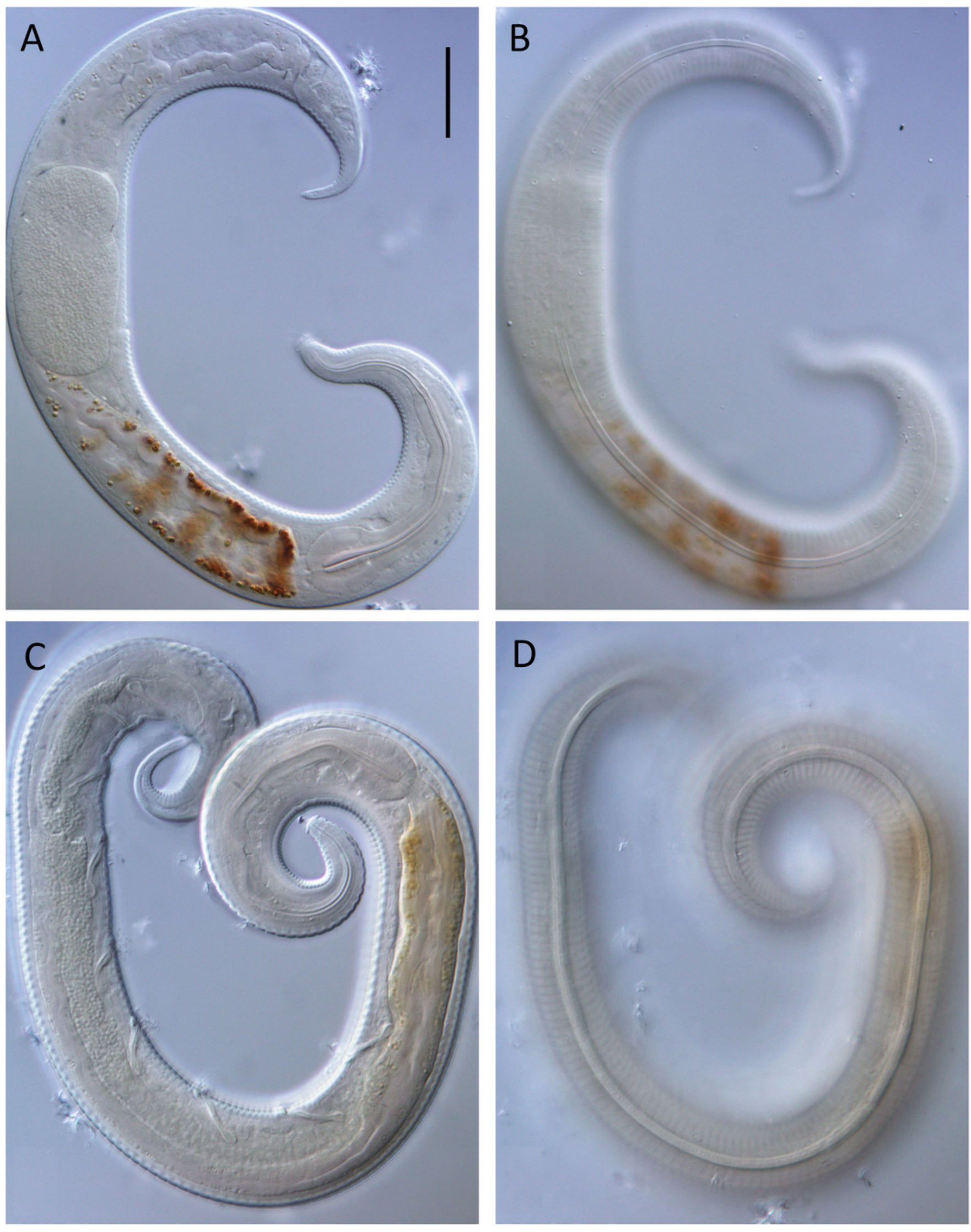


\section{Figure 4}

Leptolaimus dififtinus sp. nov. light micrographs.

Leptolaimus dififtinus sp. nov. light micrographs of male. A: Optical cross-section of pharyngeal region; B: surface view of cephalic region; C: optical cross-section of precloacal supplements; D: tail. Scale bar: $A \& B=10$ microns,$C \& D=11$ microns .
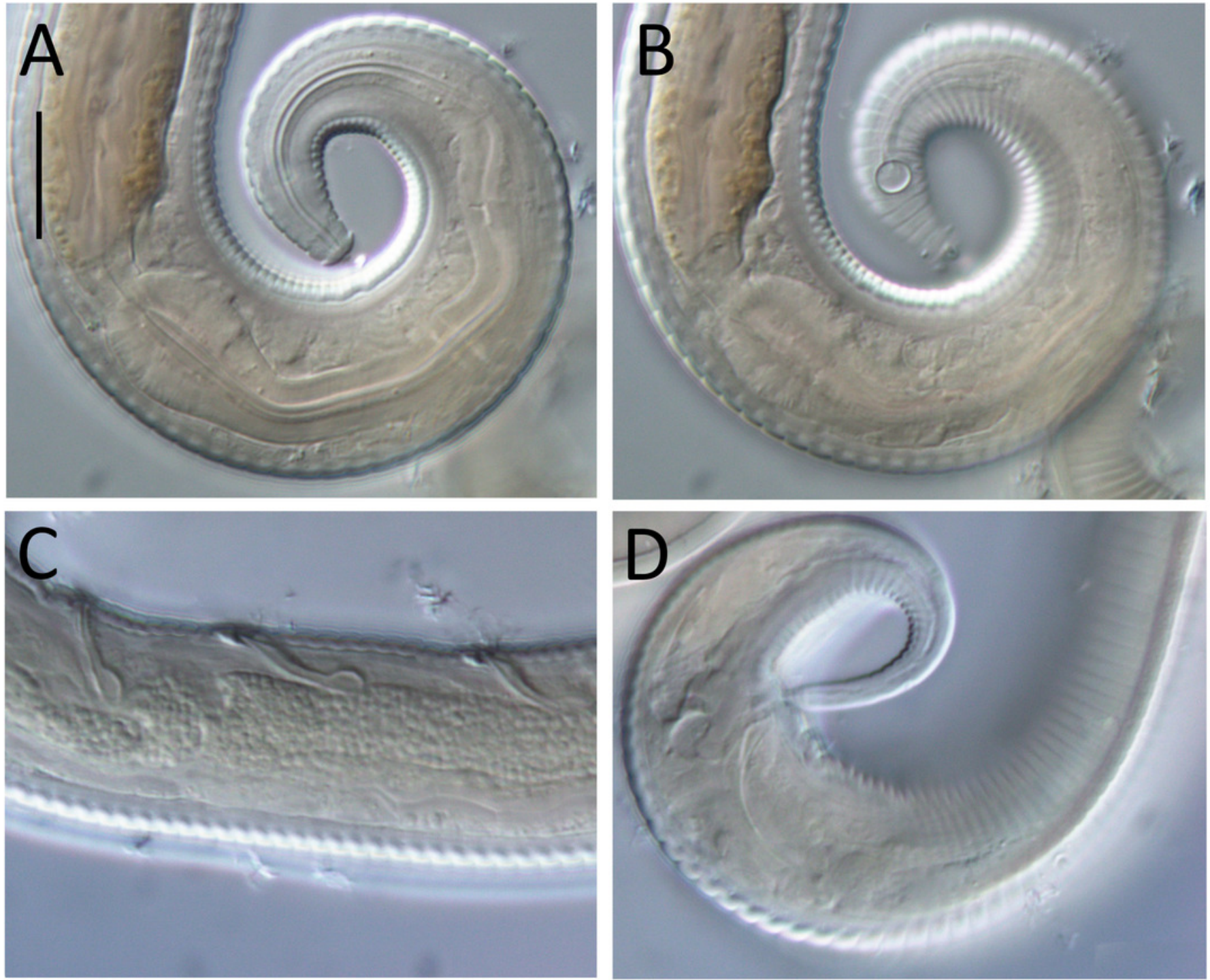
Figure 5

Lavareda iramscotti sp. nov. Drawings.

Lavareda iramscotti sp. nov. A: Anterior body region of male; B: female cephalic region;

C: juvenile cephalic region; D: male cephalic region; E: male posterior body region; F: female anterior body region; $G$ : female posterior body region. Scale bar: $A=50 \mathrm{~mm}, B, C \& D=20$ $m \mathrm{~m}, \mathrm{E}=45 \mathrm{~m} \mathrm{~m}, \mathrm{~F}=60 \mathrm{~m} \mathrm{~m}, \mathrm{G}=40 \mathrm{~m} \mathrm{~m}$. 


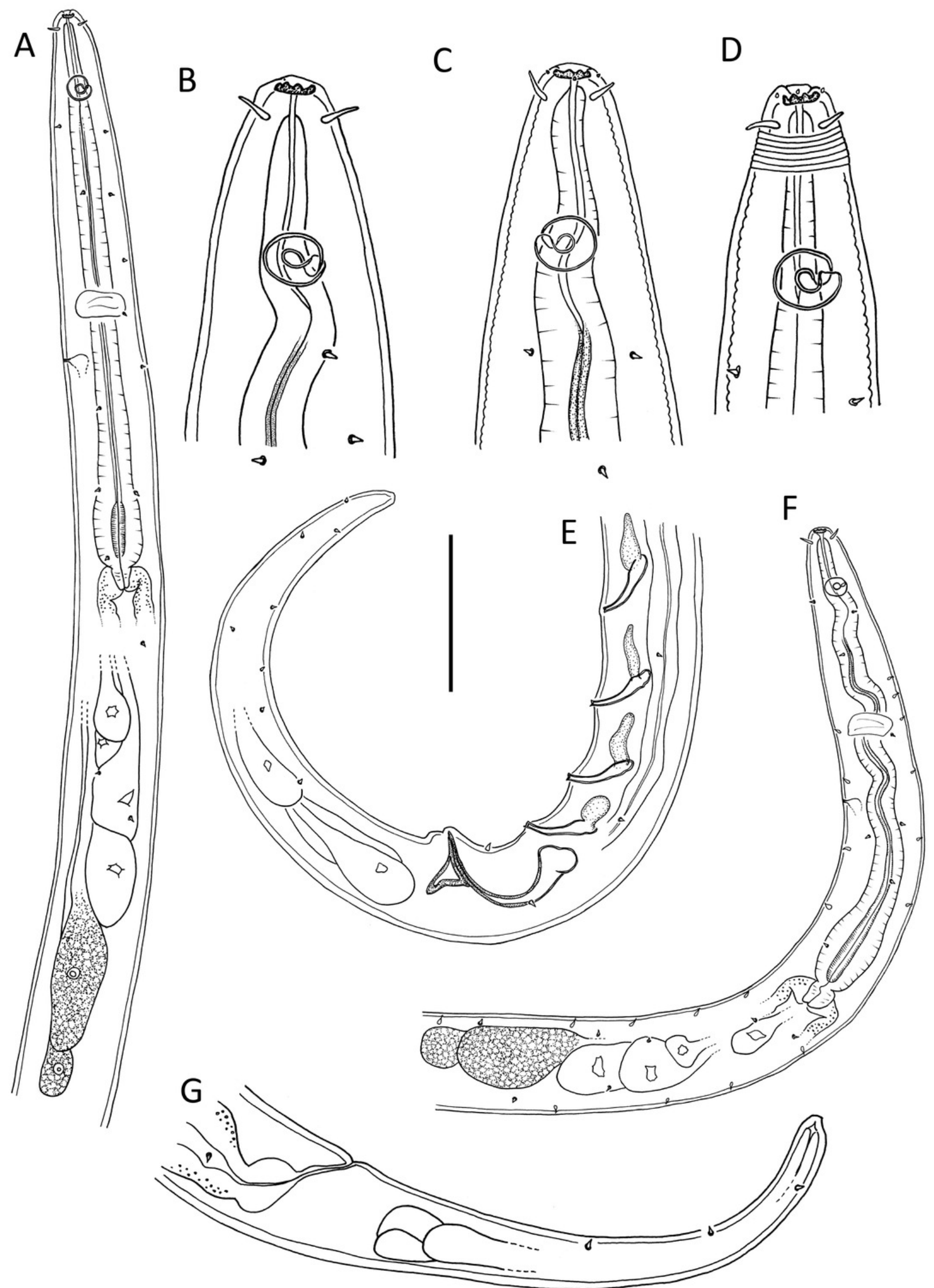


Figure 6

Lavaredairamscotti sp. nov. Drawings.

Lavareda iramscotti sp. nov. A: Entire male; $B$ : female reproductive system. Scale bar: $A=75 \mathrm{~m} \mathrm{~m}, \mathrm{~B}=$ $185 \mathrm{~m} \mathrm{~m}$. 


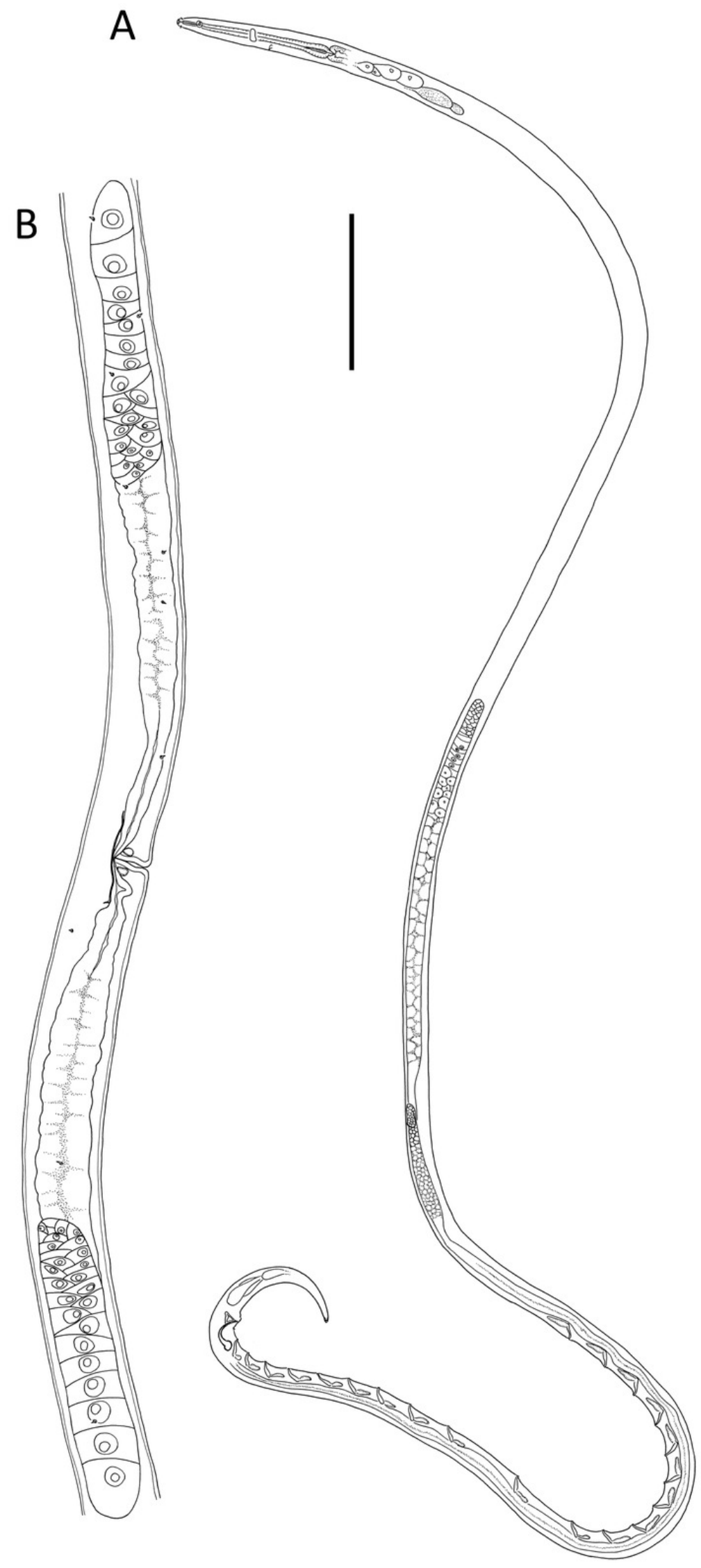


Figure 7

Lavareda iramscotti sp. nov. light micrographs ofmale.

Lavareda iramscotti sp. nov. light micrographs of male. A: Lateral surface view of anterior body region; B: optical cross-section of anterior body region; C: precloacal supplement; D: copulatory apparatus; E: tail tip and spinneret. Scale bar: A \& B $=10 \mathrm{~m} \mathrm{m,} \mathrm{C}$ $\& E=12 m m, D=14 m m$. 

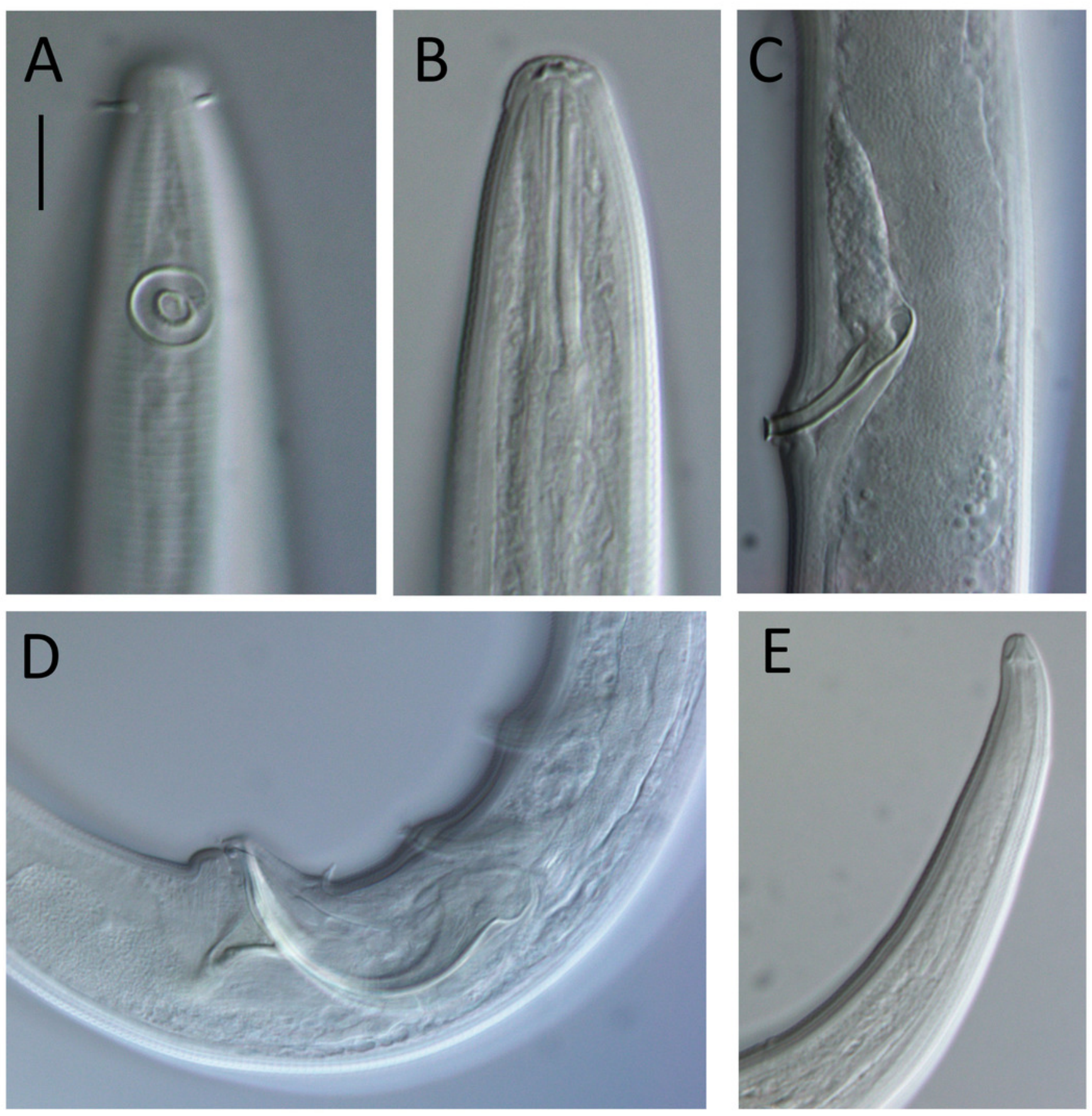